\title{
Dynamic modelling of VSC-HVDC for connection of offshore wind farms
}

\author{
Rios, Bardo; Garcia-Valle, Rodrigo
}

Published in:

9th IET International Conference on AC and DC Power Transmission

Link to article, DOI:

10.1049/cp.2010.1014

Publication date:

2011

Link back to DTU Orbit

\section{Citation (APA):}

Rios, B., \& Garcia-Valle, R. (2011). Dynamic modelling of VSC-HVDC for connection of offshore wind farms. In 9th IET International Conference on AC and DC Power Transmission (pp. 1-4). Curran Associates. IET Conference Publications No. 570 https://doi.org/10.1049/cp.2010.1014

\section{General rights}

Copyright and moral rights for the publications made accessible in the public portal are retained by the authors and/or other copyright owners and it is a condition of accessing publications that users recognise and abide by the legal requirements associated with these rights.

- Users may download and print one copy of any publication from the public portal for the purpose of private study or research.

- You may not further distribute the material or use it for any profit-making activity or commercial gain

- You may freely distribute the URL identifying the publication in the public portal

If you believe that this document breaches copyright please contact us providing details, and we will remove access to the work immediately and investigate your claim. 


\title{
DYNAMIC MODELLING OF VSC-HVDC FOR CONNECTION OF OFFSHORE WIND FARMS
}

\author{
Bardo Rios and Rodrigo Garcia-Valle \\ Centre of Electric Technology \\ Technical University of Denmark \\ Lyngby, Denmark \\ cbr@,imail.fo, rgv@,elektro.dtu.dk
}

Keywords: VSC-HVDC, grid support, voltage control, offshore wind farms.

\begin{abstract}
A VSC-HVDC (Voltage Source Converter - High Voltage Direct Current) dynamic model with a set of control strategies is developed in DIgSILENT Power-Factory with the objective of analyzing the converter's operating capability for grid support during grid faults.

The investigation is carried out based on a $165 \mathrm{MW}$ offshore wind farm with induction generators and a Low Voltage Ride-Through solution of the offshore wind turbines and Static Voltage Compensator units in the point of connection with a grid represented by a reduced four-generator power grid model.

VSC-HVDC promises to be a reliable alternative solution for interconnection with off-shore wind farms as they become larger, with a higher installed power capacity, increased number of wind turbines, and geographically situated at larger distances from suitable connection points in the transmission grids.
\end{abstract}

\section{Introduction}

Environmental constraints play an important role in the power system and specific problems are expected when renewable energies, such as large wind farms, have to be integrated into the system, particularly when connecting AC links (Alternating Current) are weak and when sufficient reserve capacity in the neighbouring systems is not available. In the future, an increasing part of the installed capacity will be connected to the distribution levels, which poses additional challenges to the planning and safe operation of the systems [1].

As offshore wind farms become larger, with a higher installed power capacity and number of wind turbines, and get located at larger distances from suitable connection points in the transmission grids, VSC-HVDC systems become relevant for grid-connection of large offshore wind farms. This at the same time means that using VSC-HVDC systems grid-code compliance from the transmission system operator must be achieved, such as grid support capability, which specifies that transmission connected power parks are to assist the power system by supplying ancillary services, such as voltage control, to secure a safe and reliable grid operation [2].

The objective within this work is to demonstrate the grid support capability of a VSC-HVDC system by means of voltage control during a grid fault in the connected $\mathrm{AC}$ network.

In order to accomplish the objective, a simple VSC-HVDC model with respective controls is built for interconnection between an off-shore wind farm and a grid as a part of a reduced four-generator power grid model. The dynamic model with a set of control strategies is developed in DIgSILENT Power- Factory (PF). The work for achieving the objective encompasses the following aspects:

- $\quad$ System model

- VSC control

- $\quad$ VSC grid support capability

\section{System model}

The approach for modelling and simulation of the VSCHVDC is to build a HVDC grid in Power Factory as an addition to the existing AC grid model represented by a reduced four-generator power grid model. The main task is to implement and control the VSC as part of the HVDC system, whose control capability is with regard to short-term voltage stability and grid support.

The model is based on self-commutating VSC based HVDC technology with a PWM technique, which in comparison with the alternative line-commutating CSC (current source converter), do not requires an AC voltage source for the commutations, and that these are practically instantaneous, whereas the duration of the commutations in LCC depends on the voltage source level and the commutation reactance. Thus, even when the firing angle is 0 , LCC consumes reactive power, the amount of which can be as much as $60 \%$ of the active power in an HVDC converter. Moreover, the reactive power requirement in $\mathrm{LCC}$ varies with the amount of active power conversion and, therefore, the converter filters and VAR compensation structures need to be adjusted as the load 
varies. VSC, on the other hand, can provide any reactive power (sink or source) independently of the active power transfer.

In LCC, as the active power transfer varies, the corresponding changes in the reactive power produce AC system voltage fluctuations. The AC voltage drops cause additional reactive power consumption and further voltage reduction, which may lead to voltage instability. To prevent the instability a minimum short-circuit ratio (SCR), defined as the ratio between the short-circuit power and converter power ratings, is required, which can be typically 2 . The VSC has no minimum SCR requirement, but the active power transfer is limited by the impedance of the AC system viewed from the converter AC terminal.

Since each arm of the converter bridge switches only once per cycle, LCC needs filters for the 12-pulse related harmonics, the filter capacity being typically 20 to $30 \%$ of the converter rating. With the use of intercycle PWM switching, or multilevel configurations in the VSC schemes, the filter requirements are drastically reduced or even eliminated altogether.

A short circuit on the inverter AC system side will cause commutation failures in the case of LCC, with temporary interruptions in the power transfer. VSC does not suffer from commutation failures and can continue to transfer active power under such condition, the amount of power being limited only by the reduction of the $\mathrm{AC}$ voltage during the fault [9].

\subsection{AC grid model}

The investigation is carried out based on a $165 \mathrm{MW}$ offshore wind farm with induction generators and a LVFRT (Low Voltage Fault Ride Through) solution of the offshore wind turbines and SVC (Static VAR Compensator) units at the point of connection with a grid represented by a reduced fourgenerator power grid model [4].

The off-shore wind farm and its components when connected to the grid by means of a HVDC system may be seen as a power source [5]. Because of the nature of a DC transmission system, faults and changes of power at the $\mathrm{AC}$ side do not considerably affect neither performance nor stability of the offshore system [6]. Therefore, it may be represented as a DC current source for modelling simplification. One has to keep in mind that is not the intention in this study to investigate the wind-farm side of the DC-link, but the grid side inverter.

The transmission network showed in Figure 2-1 will be used as platform for the investigation. This is based on a reduced model of the transmission power grid with a large offshore wind farm provided by Energinet.dk and Risø, the Danish TSO and the National Laboratory for Sustainable Energy, respectively. The reason for choosing this model as a basis for the project rather than other available, or even a simple external grid, is because it represents a more realistic case for stability studies since it was developed by the parties mentioned as a result of intensive research and development
[4]. Besides, the model includes a large off-shore wind farm representation, which serves very well as basis for comparison for this project since it uses an AC-link for interconnection with the grid and includes a solution for grid support during a grid fault. This is similar to the Danish offshore wind farm commissioned in the year 2003 at Nysted/Rødsand.

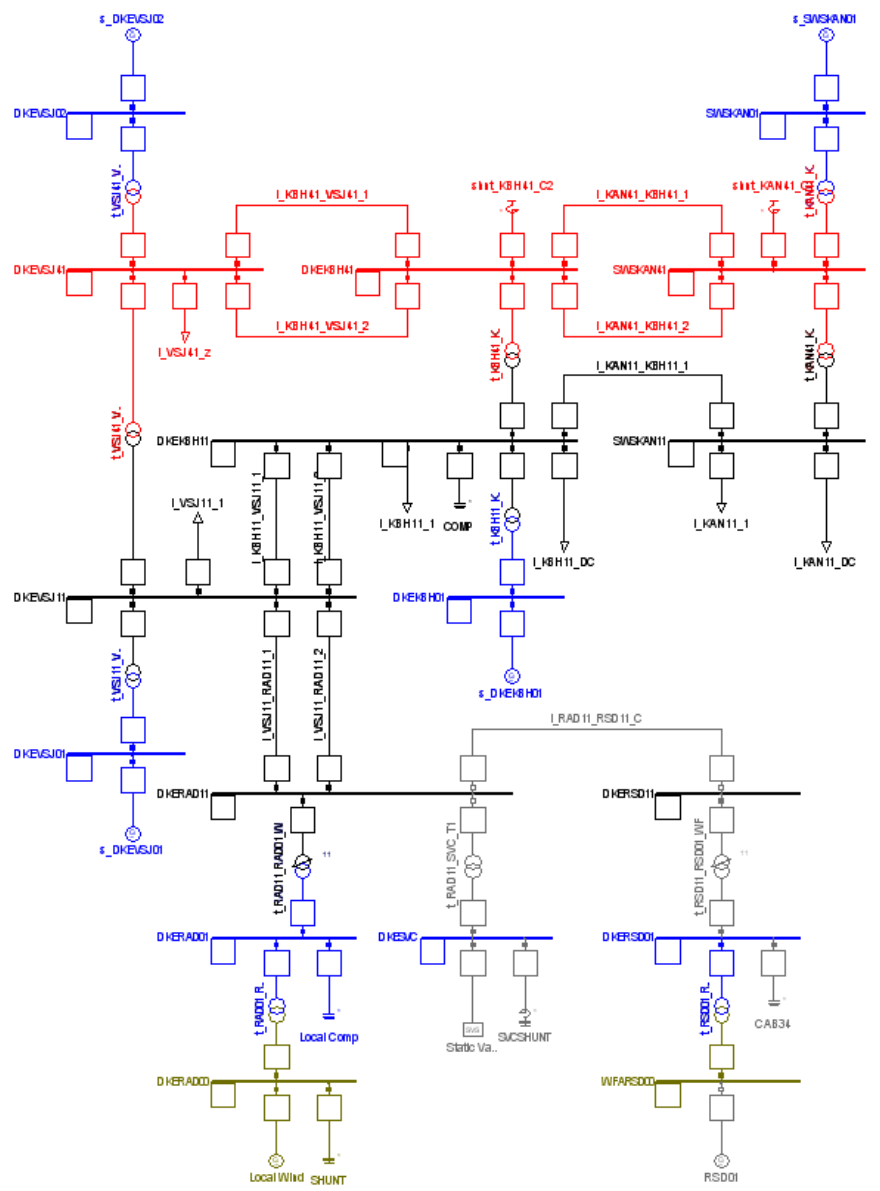

Figure 2-1: Reduced four-generator power grid model

\subsection{VSC grid model}

The VSC grid model as a replacement of the existing HVAClink (VSC-HVDC system) consists in general of three buses, a power transformer, a power converter (VSC), a DC- cable, and a DC-current source.

The offshore wind farm and AC-cable from the original model is replaced by a VSC- HVDC system. As mentioned earlier, the $165 \mathrm{MW}$ wind farm is substituted by a DC currentsource, which simplifies the model by injecting DC-current same as an off-shore wind farm will do as a complete leg system if connected to a DC-link, so it basically represents the off-shore rectifier and wind farm together. 


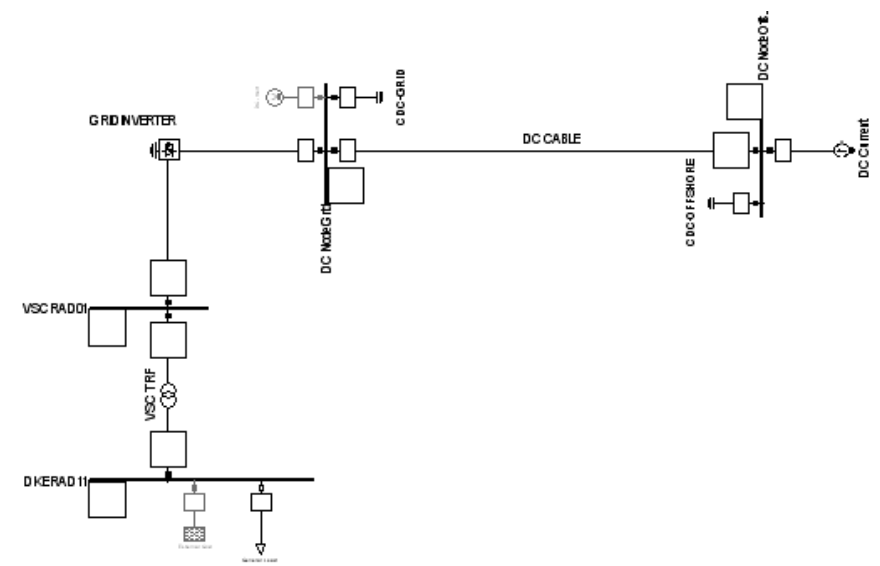

Figure 2-2: Reduced VSC grid model

\section{VSC control}

In order to achieve proper response from the HVDC system to a fault and power variation, correspondent controls for the VSC need to be implemented. The proper VSC control will allow the system to operate within the admissible ranges of control and stability improving voltage quality and grid support.

In VSC-PWM conversion the AC voltage output is varied by means of a modulation index signal defined as the ratio of the required $\mathrm{AC}$ voltage magnitude to the maximum $\mathrm{AC}$ voltage that can be generated for a given DC size capacitor.

A proposed control strategy is implemented namely vector control [7] which will be taken as modelling reference.

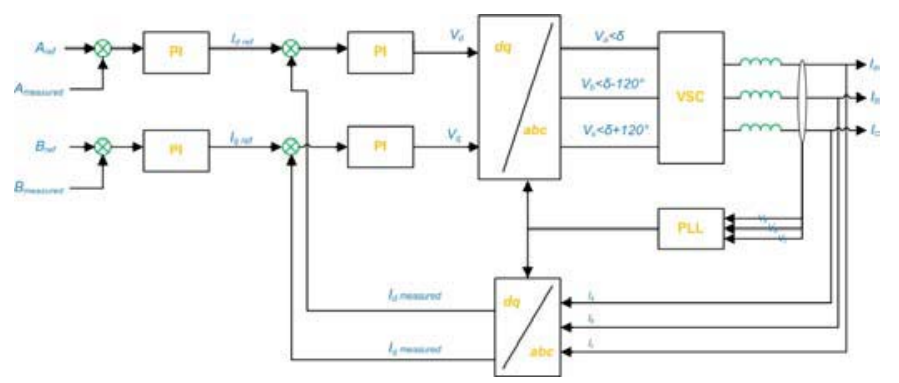

Figure 3-1: Vector control in terms of $d q$ axis current components.

Vector control strategy decouples the adjusting action of the modulation index from the phase angle. The current control attached to this strategy protects the valves from overloading, but this extra current loop slows down the speed of response.

In vector control strategy, the three-phase currents are transformed to $d q$ axes, which are then synchronized with the AC system three-phase voltage via a phase-locked loop (PLL). The $d q$ voltages generated by vector control are transformed to three-phase quantities and converted into line voltages by the VSC [7].

The grid converter operates as a controlled power source that can be managed by using voltage oriented control [8]. Power control can be performed by controlling voltage and frequency at PCC and/or improving power quality and ridethrough capability.

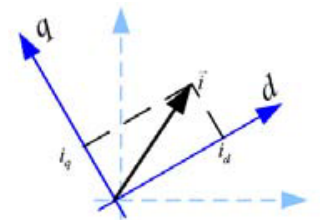

Figure 3-2: $d-q$ reference frame.

The reference current $d$-component $i d$ is controlled to perform the active power regulation while the reference current $q$ component $i q$ is controlled to obtain reactive power regulation.

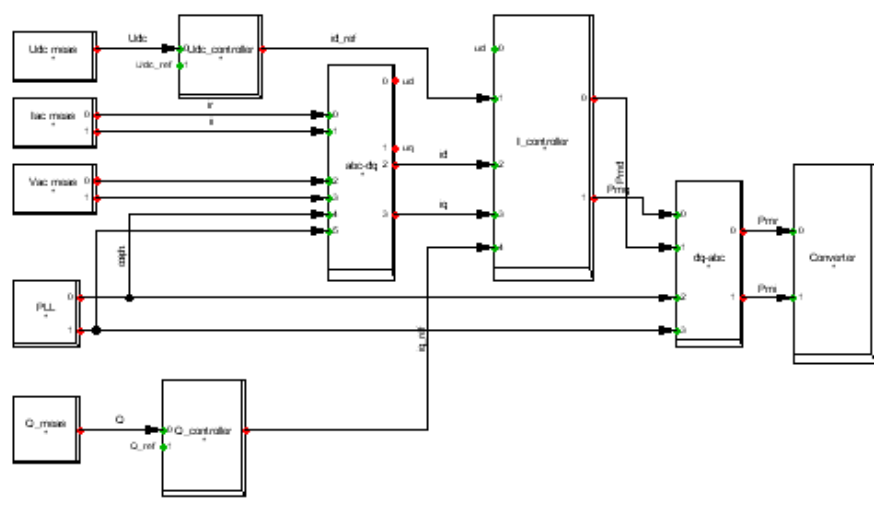

Figure 3-3: VSC control frame built in Power Factory.

\section{VSC grid support capability}

The simulation settings to test the grid support capability are based on a short-circuit event. The short-circuit event it is applied at DKEVSJ11 terminal as established in the original AC model. The response of the VSC-HVDC under this condition will determine the system's capability for grid support.

From simulation results in figure 4-1, the AC voltage drops down to $0.30 \mathrm{pu}$ at the fault's start $(1 \mathrm{~s})$, and rapidly reaches $0.70 \mathrm{pu}$ at the end of the fault $(140 \mathrm{~ms})$. Then it takes approximate $455 \mathrm{~ms}$ to reach $90 \%$ of its pre-fault value. Then it settles at between 2-3 seconds with no overshoot.

The active power drops down to about $15-20 \mathrm{MW}$ during the fault, and then rises sharply causing short oscillations with some overshoots before smoothly reaching to its pre-fault value at 3-4 seconds.

The SVC is able to support in the fault event by injecting its reactive power capability to the grid during the fault in an action to counter the drop in the AC terminal voltage, and it decreases as voltage recovers from the fault. The implemented control mode decreases slower resulting in the slower voltage raise but with basically no oscillations. 

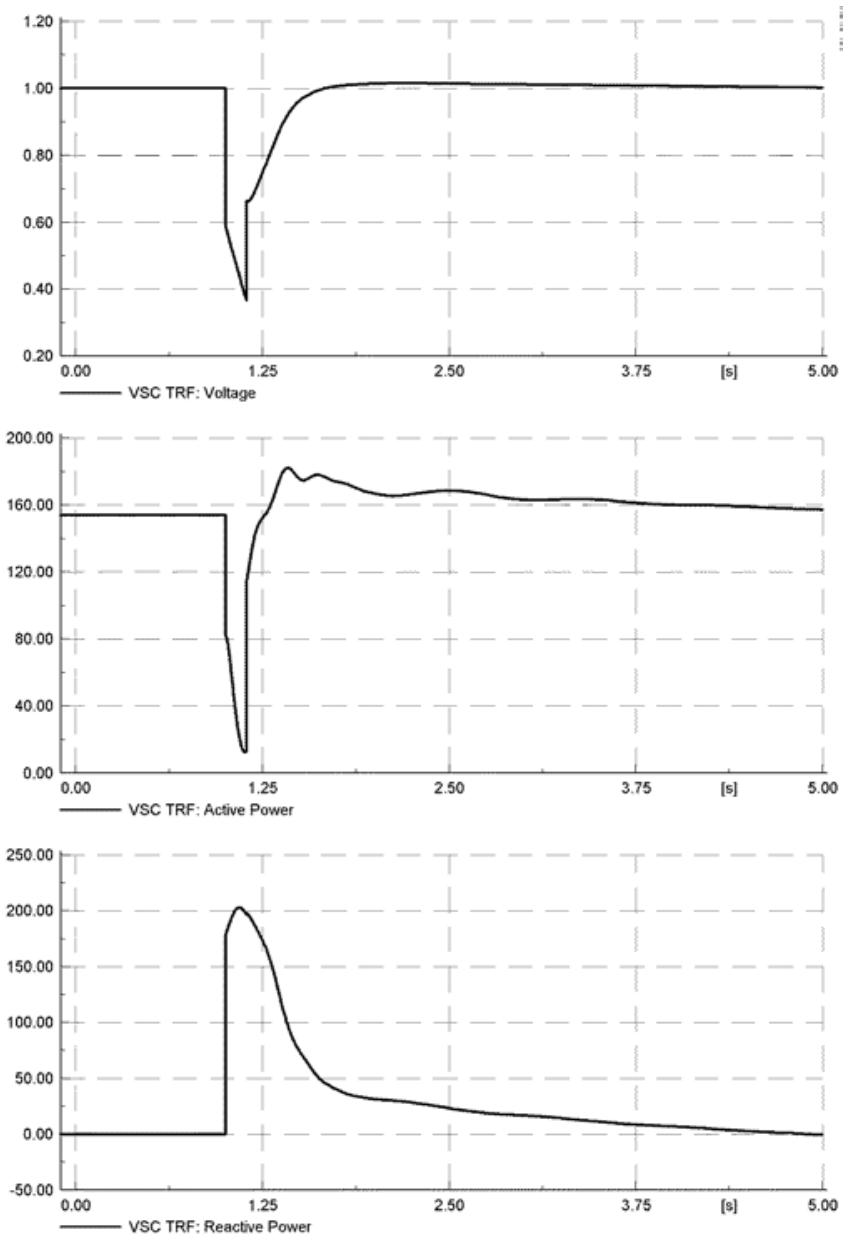

Figure 4-1: Voltage (a), active power (b), and reactive power (c) during the short circuit event.

VSC-HVDC manages to control the reactive power efficiently, helping the voltage to re-establish quickly by injecting reactive power during the duration of the fault to then diminishing smoothly without oscillating. The same way, the DFIG wind farm equipped with voltage control manages to re-establish the voltage rapidly by controlling the reactive power supply injected to the grid during the fault [4], but fluctuating down to negative reactive power for finally reaching stability over $10 \mathrm{sec}$.

In the plots, the influence of grid support capability can be seen during the fault by supplying reactive power, and after the fault, by controlling the voltage.

\section{Conclusions}

VSC-HVDC proves to be an suitable alternative for interconnection with offshore wind farms as they become larger, with a higher installed power capacity, increased number of wind turbines, geographically situated at larger distances from suitable connection points in the transmission grids.

The simulation results demonstrate the grid support capability of the VSC-HVDC by means of contributing with reactive power and helping therefore to re-establish the grid's voltage during the fault.

VSC-HVDC systems become relevant for grid-connection of large offshore wind farms since its control capability and flexibility enables grid-code compliance required from the transmission system operators.

\section{References}

[1] Power T\&D Siemens. "HVDC Plus-Basics and Principle of Operation", Siemens Energy Sector Power Transmission Solutions, 2008.

[2] A.D. Hansen, G. Michalke. "Wind turbine's grid support capability in uninterrupted operation," IET, vol. 3, no. 3, pp. 333-348, 2008.

[4] Akhmatov, Lund, Hansen, Sørensen, Nielsen. A Reduced Wind Power Grid Model for Research and Education, Energinet DK, Riso National Laboratory, CET-DTU, 2006.

[5] Simon P. Teeuwsen. "Simplified Dynamic Model of a Voltage-Sourced Converter", IEEE, no. 978-1-4244-38112/09/, 2009.

[6] Gerd Balzer, Ervin Spahic. "Impact of the VSC-HVDC connection of large offshore wind farms on power system stability and control", Germany, IEEE 978-1-4244- 2190-9, 2007.

[7] Arriaga, Liu, Watson. "Flexible Power Transmission-The HVDC Options", Wiley, 2007, pp. 1-19.

[8] Marco Liserre. "Grid converter control and future functions", IET AAU, DK, 2009.

[9] Arriaga, Liu, Watson. "Flexible Power Transmission-The HVDC Options", Wiley, 2007, pp. 114.

\section{Biographies}

Bardo Rios received his Engineering degree from Chihuahua Institute of Technology ITCH Mexico and obtained a MSc in Electrical Engineering with specialisation in wind-energy from Technical University of Denmark DTU in 2009.

He has worked on a project basis as research assistant with Siemens Germany within HVDC-plus technology, and has several years of experience working with electrical power marine systems and telecommunications.

Rodrigo Garcia-Valle received the electrical engineering degree from the National Polytechnic Institute of Mexico, in 2001, the MSc degree from CINVESTAV, Guadalajara, Mexico, in 2003 and obtained his $\mathrm{PhD}$ degree from the University of Glasgow, U.K., in 2007. In 2008, he was granted with the Hans Christened Ørsted Award at the Centre for Electric Technology (CET) by the Technical University of Denmark to carry out postdoctoral research activities. Since 2009 he holds the position as Assistant Professor. His research interests are dynamics, stability and control of electric power systems; artificial intelligence techniques; renewable energy integration; and modelling and simulation of FACTS and custom power controllers. He is an IEEE, IET and CIGRE member. 